\title{
Clade-Specific Biosurveillance of Pseudoperonospora cubensis Using Spore Traps for Precision Disease Management of Cucurbit Downy Mildew
}

\author{
A. Rahman, J. R. Standish, K. N. D'Arcangelo, and L. M. Quesada-Ocampo ${ }^{\dagger}$
}

Department of Entomology and Plant Pathology, North Carolina State University, Raleigh, NC 27695-7613

Accepted for publication 2 August 2020.

\begin{abstract}
Pseudoperonospora cubensis is an obligate oomycete and cause of cucurbit downy mildew (CDM), the most destructive foliar disease affecting cucurbit hosts. Annual epidemics develop throughout the United States as windborne sporangia travel great distances and survive prolonged exposure to solar radiation. Recent genomic evidence suggests that $P$. cubensis isolates display host adaptation based on their respective clade. Early detection is key for fungicide application timing, and identification of the host-adapted clade provides information on the risk of infection for specific cucurbit crops. In this study, a multiplex quantitative PCR assay was developed based on species- and cladespecific nuclear genomic markers. The assay detected as few as 10 sporangia or DNA at $100 \mathrm{fg} / \mathrm{ml}$ for both clades and was validated in the
\end{abstract}

ABSTRACT field by deploying rotorod spore samplers in cucurbit sentinel plots located at two research stations in North Carolina. Using this assay, sporangia DNA was detected in spore trap sampling rods before signs of P. cubensis or CDM symptoms were observed in the sentinel plots. Both clade 1 and clade 2 DNA were detected in late-season cucumber and watermelon plots but only clade 2 DNA was detected in the early-season cucumber plots. These results will significantly improve disease management of CDM by monitoring inoculum levels to determine the cucurbit crops at risk of infection throughout each growing season.

Keywords: disease control and pest management, epidemiology, oomycetes, pathogen detection
Pseudoperonospora cubensis is an obligate oomycete and the causal agent of cucurbit downy mildew (CDM), a devastating disease of cucurbits worldwide (Salcedo et al. 2020). In 2004, a population shift in $P$. cubensis resulted in an epidemic that devastated cucurbit crops along the Atlantic coast of the United States (Holmes et al. 2015). Previously resistant cucumber varieties and fungicides that had been effective for CDM management were no longer effective after 2004 (Savory et al. 2011). Due to the impact of the CDM epidemic on U.S. agriculture (Beans 2018), several studies were completed to characterize pathogen populations (Naegele et al. 2016; QuesadaOcampo et al. 2012; Summers et al. 2015b; Wallace and QuesadaOcampo 2017; Wallace et al. 2020) and generate new management strategies (Call et al. 2012; Goldenhar and Hausbeck 2019; Summers et al. 2015a; Withers et al. 2016).

Recently, two host-specialized clades of $P$. cubensis were described: clade 1 and clade 2 . Clade 1 isolates preferentially infect acorn squash (Cucurbita pepo L.), pumpkin (C. maxima Duchesne.), butternut squash (C. moschata Duchesne ex Poir.), watermelon (Citrullus lanatus (Thunb.) Matsum \& Nakai), and the wild hosts bitter melon (Momordica charantia L.) and balsam apple (M. balsamina L.). Clade 2 isolates preferentially infect cucumber (Cucumis sativus L.), cantaloupe (C. melo L.), and the wild host bottle gourd (Lagenaria siceraria (Molina) Standl.) (Wallace et al.

†Corresponding author: L. M. Quesada-Ocampo; lmquesad@ncsu.edu

Funding: This work was supported by Pickle Packers International, the United States Department of Agriculture (USDA) Animal and Plant Health Inspection Service Awards 13-8130-0254-CA and 13-8130-0274-CA, the USDA National Institute of Food and Agriculture Award 2016-68004-024931, the USDA North Carolina Department of Agriculture Specialty Crop Block Grant Program Awards 12-25-B-16-88 and 15SCBGP0003, and the North Carolina State Hatch Project Numbers NC02418 and NC02628.

*The $\boldsymbol{e}$-Xtra logo stands for "electronic extra" and indicates that a supplementary file, supplementary figures, and one supplementary table are published online.

The author(s) declare no conflict of interest.

(C) 2021 The American Phytopathological Society
2020). In addition to host preference, $P$. cubensis clades showed some fluctuation by season and location within North Carolina (Wallace et al. 2020), highlighting the importance of local cucurbit acreage in influencing inoculum composition at a given time or location (Ojiambo et al. 2015). Currently, management of CDM relies heavily on frequent fungicide applications with effective products (Goldenhar and Hausbeck 2019). To reduce fungicide applications, producers are recommended to begin applying fungicides preventatively only once the disease has been reported in a neighboring state through the CDM ipmPIPE (Ojiambo et al. 2011). However, previous studies have shown that $5 \%$ of reports do not correspond with the expected movement of the disease from southeastern to northeastern U.S. states along the Atlantic coast (Ojiambo and Holmes 2011). This may be due, in part, to yearround greenhouse production acting as a source of inoculum in some regions (Naegele et al. 2016), or to wild cucurbits serving as reservoirs of $P$. cubensis (Runge and Thines 2009; Wallace and Quesada-Ocampo 2015; Wallace et al. 2014). The CDM ipmPIPE relies on reported outbreaks of commercial cucurbits but does not account for other sources of inoculum; as a result, researchers have developed complementary alert systems for detecting $P$. cubensis airborne inoculum (Granke and Hausbeck 2011; Granke et al. 2014; Rahman et al. 2017; Summers et al. 2015a). Spore traps have been used successfully to detect $P$. cubensis sporangia in air currents; however, increasing acreage of hop in the eastern United States has become a confounding factor to the detection of $P$. cubensis (Crandall et al. 2018; Rahman et al. 2017). The hop downy mildew pathogen, $P$. humuli, is a sister species to $P$. cubensis that cannot be distinguished morphologically and has impeded positive identification in areas where both cucurbit and hop are produced (Purayannur et al. 2020). This hindrance has prompted efforts to generate species-specific molecular assays for both pathogens (Rahman et al. 2019; Summers et al. 2015a; Withers et al. 2016). While describing species-specific markers for $P$. cubensis, Withers et al. (2016) identified marker c2555.3e7 that displayed variation depending on the host of origin for individual $P$. cubensis isolates.

In this study, we confirm that the observed polymorphism in marker c2555.3e7 corresponds to the host-adapted P. cubensis 
clades described by (Wallace et al. 2020). We then build on this finding in order to (i) develop a $P$. cubensis clade-specific assay to estimate the risk of specific cucurbit crops becoming infected by P. cubensis, (ii) develop P. cubensis clade-specific multiplex quantitative PCR (qPCR) assays for detecting and quantifying $P$. cubensis airborne sporangia, and (iii) validate the assays by sampling airborne sporangia in cucurbit fields using rotorod spore traps. This work is the first step toward developing a comprehensive biosurveillance system for $P$. cubensis that combines information on inoculum level with risk of infection for specific cucurbit crops and will be useful to inform crop-specific fungicide application timing based on the host-adapted clade. Such a strategy will allow for fungicides to be applied only to at-risk crops, which is likely to reduce economic losses and preserve fungicide efficacy by reducing unnecessary selection for fungicide resistance.

\section{MATERIALS AND METHODS}

Analyzing polymorphic diagnostic marker c2555.3e7 for assay development. The previously identified candidate genomic marker $2555.3 \mathrm{e} 7$ of $P$. cubensis exhibited polymorphism by host of origin (Withers et al. 2016) and was used for the development of a diagnostic multiplex qPCR assay. Two host-adapted clades were described for $P$. cubensis by Wallace et al. (2020), and 10 isolates representing each clade were identified for assay design and validation in our study (Table 1). To confirm clade correspondence for these 20 isolates, marker c2555.3e7 was amplified using primers sw552 and sw553 in conjunction with genomic DNA that had previously been extracted and genotyped (Wallace et al. 2020; Withers et al. 2016). Once the polymorphism of marker c2555.3e7 was confirmed (Fig. 1), DNA of P. cubensis isolates in our longterm collection were used to amplify c2555.3e7 and identify a representative isolate for each clade that could be used to propagate sporangia for subsequent experiments. Single-sporangium isolates on infected leaves and DNA are stored at $-80^{\circ} \mathrm{C}$ in our long-term collection. This initial experiment resulted in P. cubensis isolates SC1982 and MSU-1, being selected as representatives of clade 1 and clade 2, respectively, for assay development (Fig. 1).

Products obtained after amplification of c2555.3e7 in clade 1 SC1982 and clade 2 MSU-1 were sequenced using Sanger technology on a 3730XL DNA Analyzer (Applied Biosystems, Foster City, CA, U.S.A.) by the North Carolina State Genomic Sciences Laboratory (Raleigh, NC, U.S.A.). The resulting sequences were aligned to the MSU-1 genome sequence (Savory et al. 2012a,b) and the universal forward primer ar1517 was designed to be used with the sw553 reverse primer for amplifying the polymorphic region of $\mathrm{c} 2555.3 \mathrm{e} 7$ in an additional 97 P. cubensis isolates. These isolates were collected from multiple host plants grown in different regions of the United States (Supplementary Table S1; Fig. 2). After confirming clade correspondence, the polymorphic region of $\mathrm{c} 2555.3 \mathrm{e} 7$ was used to develop a multiplex qPCR assay to detect and quantify the specific clades of $P$. cubensis as described below.

Propagating, counting, and extracting genomic DNA from $\boldsymbol{P}$. cubensis sporangia. Isolates of $P$. cubensis were propagated for sporangia development following the same method as described previously (Withers et al. 2016). For each isolate, a sporangial suspension of 1 to $5 \times 10^{4}$ sporangia/ml was spray inoculated on the abaxial surface of detached cucumber leaves placed upside down on moist sterile paper towels in plastic boxes. Inoculated leaves were incubated at 21 and $18^{\circ} \mathrm{C}$ with a cycle of $12 \mathrm{~h}$ of light and $12 \mathrm{~h}$ of darkness, respectively, in a precision plant growth chamber (Thermo Fisher Scientific, Waltham, MA, U.S.A.). Using a Preval sprayer (Preval, Bridgeview, IL, U.S.A.), sterile water was used to dislodge sporangia from leaves; this leaf wash was passed through sterile $40-\mu \mathrm{m}$ cell strainers (Genesee Scientific, San Diego, CA, U.S.A.) and collected into a sterile 50-ml tube. The spores from the leaf wash were then centrifuged at $10,000 \times g$ for
5 min at $4{ }^{\circ} \mathrm{C}$, the supernatant was decanted, and the spore pellet transferred to a $1.5-\mathrm{ml}$ microcentrifuge tube. All spore pellet tubes were stored at $-20^{\circ} \mathrm{C}$ until needed for further experiments.

Eight distinct $P$. cubensis sporangia counts $(1,10,20,50,100$, 200,500 , and 1,000 sporangia) were generated on rotorod spore sampling rods coated in vacuum grease (Dow Corning, SigmaAldrich, Inc., St. Louis, MO, U.S.A.) from both SC1982 and MSU1. To obtain counts of $1,10,20$, and 50 fresh $P$. cubensis sporangia, a handmade sterile glass needle method (Goh 1999) was used to collect individual sporangium from sparsely sporulating cucumber leaves. Under a dissecting microscope (Leica M205C stereomicroscope; Leica Microsystems Inc., Chicago, IL, U.S.A.), a single sporangium on the ultimate branchlets of sporangiophores was picked up using the tip of a glass needle and dragged on a greasecoated sampler rod. Dark melanized $P$. cubensis sporangia added to colorless silicone grease-coated white sampler rods were counted under the dissecting scope. Sporangiophores were very rarely encountered in this process and, whenever present, or if an undesired number of sporangia were accidentally added to the rod, the rod was discarded. To obtain counts of 100, 200, 500, and 1,000 sporangia, a suspension of $P$. cubensis sporangia was quantified using a hemocytometer and an appropriate aliquot was dispensed on grease-coated sampler rods. For each count of $P$. cubensis sporangia, 10 sampler rods were prepared. Each prepared sampler rod was placed in a sterile 2-ml screw-cap microcentrifuge tube and stored at $-20^{\circ} \mathrm{C}$ until use. Genomic DNA extracted from silicone grease-coated sampler rods without the presence of any sporangia was used as a negative control.

DNA extraction from $P$. cubensis sporangia and infected or uninfected leaf tissue was performed using a phenol-chloroform DNA extraction method as previously described (Withers et al. 2016), with minor modifications. A 50- $\mu$ l sporangial suspension, a 2- to 3-mm infected leaf segment, or other oomycete mycelial tissue was collected in a $1.5-\mathrm{ml}$ microcentrifuge tube with approximately $200 \mu \mathrm{l}$ of 425 - to 600 -mm acid-washed glass beads (Sigma-Aldrich, Inc.) and $500 \mu \mathrm{l}$ of extraction buffer $(200 \mathrm{mM}$ Tris- $\mathrm{HCl}$ [pH 8], $250 \mathrm{mM} \mathrm{NaCl}, 25 \mathrm{mM}$ EDTA, $0.5 \%$ sodium dodecyl sulfate, and $0.5 \%$ Triton X-100). Additionally, three 2.3-mm Zircon beads (Biospec, Bartlesville, OK, U.S.A.) were added to infected leaf lesions tubes. Sporangia tubes were vortexed horizontally for $5 \mathrm{~min}$ whereas leaf lesion tissues were lysed using an OMNI International BeadRuptor (OMNI International, Tulsa, OK, U.S.A.). Following tissue lysis, RNase $(30 \mathrm{mg} / \mathrm{ml})$ and proteinase $\mathrm{K}(50 \mathrm{mg} / \mathrm{ml})(\mathrm{G}-$ Biosciences, St. Louis, MO, U.S.A.) were added and incubated at $65^{\circ} \mathrm{C}$ for $30 \mathrm{~min}$ in two subsequent steps. Subsequently, $\beta$-mercaptoethanol $(20 \mu \mathrm{l} / \mathrm{ml})$ was added to all samples and centrifuged at $21,000 \times g$ for $15 \mathrm{~min}$; the resulting aqueous phase was then subjected to an equal volume of saturated phenol $(\mathrm{pH} 8)$ and to chloroform-isoamyl alcohol (24:1) extraction. DNA was then precipitated with 0.8 volume of $100 \%$ ice-cold isopropanol (30 to $60 \mathrm{~min}$ at $-20^{\circ} \mathrm{C}$ ), washed with $500 \mu \mathrm{l}$ of $70 \%$ ethanol, dried, and resuspended in $100 \mu \mathrm{l}$ of $10 \mathrm{mM}$ Tris-HCl. Extracted DNA was quantified using the Qubit dsDNA HS assay (Life Technologies, Carlsbad, CA, U.S.A.). DNA extractions from spore trap sampler rods were performed using the NucleoSpin Plant II kit according to manufacturer's instructions, with minor modifications (Klosterman et al. 2014). In brief, pairs of sampler rods collected in 2-ml screwcap tubes were first centrifuged at $21,000 \times g$ for $20 \mathrm{~min}$; then, the sampler rods were removed and acid-washed glass beads were added along with $300 \mathrm{ml}$ of buffer PL1, vortexed horizontally for $5 \mathrm{~min}$, and incubated at $65^{\circ} \mathrm{C}$ for $10 \mathrm{~min}$. RNase A was added to the samples (according to the manufacturer's instructions), which were then heat treated and vortexed before further processing, as described by Klosterman et al. (2014).

Conventional end-point PCR and cleanup for sequencing. Primers for PCR and sequencing (Table 2) were ordered through IDT (Integrated DNA Technologies, Coralville, IA, U.S.A.) or Eton Bioscience (Research Triangle, NC, U.S.A.). The PCR assays were 
completed as previously described (Withers et al. 2016), except the annealing temperatures (Ta) were set according to Table 2. Amplicon clean-up from PCR assays and agarose gel extraction were completed using ExoSAP-IT (Thermo Fisher Scientific) and the Promega Wizard SV Gel and PCR Cleanup System (Fisher Scientific, Hampton, NH, U.S.A.), respectively, according to manufacturer's instructions.

Design of primers, probes, and the qPCR assay. Cladespecific primers and locked nucleic acid (LNA) probes were designed using Geneious 10.2.3 (Biomatters, Auckland, New Zealand) to target the polymorphic region of c2555.3e7 (Table 2; Fig. 2) following the previously described guidelines (Bustin et al. 2009; Rodriguez et al. 2015) and analyzed for homo- and heterodimer binding strength using the OligoAnalyzer Tool (Integrated DNA Technologies, Inc.). The LNA probe specific for clade 1 isolates was HEX dye labeled (ar1497) whereas, for clade 2, it was FAM dye labeled (ar1529), and both had Iowa BlackÒ as a quencher. The internal control (IC) probe was labeled with $\mathrm{Cy} 5$, with Iowa BlackÒ Dark as a quencher (Table 2). A 20- $\mu$ l multiplexed qPCR mix contained $1 \times$ PerfeCta Multiplex qPCR ToughMix (QuantaBio, VWR, Beverly, MA, U.S.A.), $2 \mathrm{mM}$ $\mathrm{MgCl}_{2}, 750 \mathrm{nM}$ universal forward primer, $500 \mathrm{nM}$ each reverse primer, $100 \mathrm{nM}$ each LNA probe, and $2 \mu \mathrm{l}$ of template DNA ( $1 \mu \mathrm{l}$ from each clade for mixed DNA or from spore trap samples) or $1 \mu \mathrm{l}$ of DNA when only one clade was used, unless otherwise stated. For a singleplex qPCR, a similar $20-\mu$ l reaction volume, $500 \mathrm{nM}$ primers, and $100 \mathrm{nM}$ LNA probe (either clade 1 or 2 ) were used. The CFX 96 Touch qPCR system (Bio-Rad, Hercules, CA, U.S.A.) and Bio-Rad CFX Manager software (Bio-Rad) were used to run all qPCR assays in hard-shell 96-well plates (Bio-Rad recommended), with a reaction profile of $5 \mathrm{~min}$ at $95^{\circ} \mathrm{C}$ for initial denaturation followed by 38 cycles of $95^{\circ} \mathrm{C}$ for $15 \mathrm{~s}$ and $65^{\circ} \mathrm{C}$ for $1 \mathrm{~min}$.

Specificity and detection limits of the qPCR assay. DNA from different sporangial counts and 10-fold serial dilutions of total genomic DNA ranging from $1 \mathrm{ng} / \mu \mathrm{l}$ to $1 \mathrm{fg} / \mu \mathrm{l}$ from both SC1982 (clade 1) and MSU-1 (clade 2) were used to determine the specificity and detection limits of the multiplex qPCR assay. All

TABLE 1. Isolates of Pseudoperonospora cubensis collected from North Carolina used to validate clade-specificity of molecular markers and assays

\begin{tabular}{|c|c|c|c|c|c|c|}
\hline \multirow[b]{2}{*}{ Isolate $^{\mathrm{b}}$} & \multirow[b]{2}{*}{ Year } & \multirow[b]{2}{*}{ Host $^{\mathrm{c}}$} & \multicolumn{2}{|c|}{$\mathrm{K}$ value ${ }^{\mathrm{a}}$} & \multicolumn{2}{|c|}{ Clade } \\
\hline & & & $\mathrm{K} 1$ & $\mathrm{~K} 2$ & PCR & $\mathrm{qPCR}^{\mathrm{d}}$ \\
\hline KIN-1-7 & 2013 & Cucumis sativus & 0.010 & 0.990 & 2 & 2 \\
\hline KIN-1-10 & 2013 & C. sativus & 0.009 & 0.991 & 2 & 2 \\
\hline CLE-1-2 & 2013 & C. sativus & 0.009 & 0.991 & 2 & 2 \\
\hline 14CLE2-1-2B & 2014 & C. sativus & 0.008 & 0.992 & 2 & 2 \\
\hline 14CLE2-1-11A & 2014 & C. sativus & 0.008 & 0.992 & 2 & 2 \\
\hline 14KIN-3-5D & 2014 & C. melo & 0.009 & 0.991 & 2 & 2 \\
\hline 14KIN-3-1C & 2014 & C. melo & 0.007 & 0.993 & 2 & 2 \\
\hline 14KIN2-3-2A & 2014 & C. melo & 0.008 & 0.992 & 2 & 2 \\
\hline 14CLE-3-8 & 2014 & C. melo & 0.006 & 0.994 & 2 & 2 \\
\hline 14WAY2-3-1B & 2014 & C. melo & 0.010 & 0.990 & 2 & 2 \\
\hline KIN2-6-4 & 2013 & Cucurbita moschata & 0.990 & 0.010 & 1 & 1 \\
\hline 14KIN2-6-6A & 2014 & C. moschata & 0.989 & 0.011 & 1 & 1 \\
\hline 14WAY2-6-2A & 2014 & C. moschata & 0.985 & 0.015 & 1 & 1 \\
\hline WAY2-4-15 & 2013 & C. реро & 0.983 & 0.017 & 1 & 1 \\
\hline WAY2-4-14 & 2013 & C. реро & 0.992 & 0.008 & 1 & 1 \\
\hline 14KIN2-4-3B & 2014 & C. реро & 0.972 & 0.028 & 1 & 1 \\
\hline WAY2-5-14 & 2013 & C. maxima & 0.990 & 0.010 & 1 & 1 \\
\hline 14CLE2-5-4C & 2014 & C. maxima & 0.990 & 0.010 & 1 & 1 \\
\hline CLE-7-11 & 2013 & Citrullus lanatus & 0.992 & 0.008 & 1 & 1 \\
\hline CLE-7-7 & 2013 & C. lanatus & 0.991 & 0.009 & 1 & 1 \\
\hline
\end{tabular}

a $\mathrm{K}$ groupings determined through Bayesian clustering and allele frequency correlations as described by Wallace et al. (2020).

b Isolates collected as part of a study described by Wallace et al. (2020).

c Cucumis sativus $=$ cucumber, $C$. melo $=$ cantaloupe, Cucurbita moschata $=$ butternut squash, $C$. pepo $=$ acorn squash, $C$. maxima $=$ pumpkin, and Citrullus lanatus $=$ watermelon.

d Quantitative PCR. other infected plant tissue samples tested were adjusted to a DNA concentration of $1 \mathrm{ng} / \mu \mathrm{l}$ before testing. All total genomic DNA concentrations for each clade isolate were tested individually and in all possible concentration combinations with the opposing clade DNA. Additionally, SC1982 and MSU-1 DNA from the different sporangial counts were used in singleplex and multiplex qPCR assays to confirm the specificity and determine the detection sensitivity of clade-specific sporangial DNA.

Spore trap setup, sampler rod collection, and CDM disease monitoring. Battery-powered impaction-type rotorod spore samplers (Model 82; Sampler Technologies, Inc.) were placed in cucurbit sentinel plots for trapping $P$. cubensis aerial sporangia on two sampler rods ( 2 by 2 by $32 \mathrm{~mm}$ ) (Fig. 3) using a procedure described previously (Neufeld et al. 2013). The sentinel plots were planted twice per year in 2016 and 2017 at the Central Crops Research Station (CCRS; located in Clayton, NC) and the Cunningham Research Station (CURS; located in Kinston, NC), in late April to early May and again in early August of both years. One spore trap was placed adjacent to the cucumber plot and another one adjacent to the butternut squash plot. The traps were operated from May to September each year, and sampler rods from each spore trap at the CCRS were collected 4 days per week (Tuesday to Friday) and 2 days per week at the CURS (Tuesday and Friday). The collected sampler rods were stored at $-20^{\circ} \mathrm{C}$ until DNA extraction, which was then analyzed using the clade-specific multiplex qPCR assay to detect the presence of airborne sporangia. As mentioned above, two samplers were placed at each plot and the sampler rods with the lower cycle threshold $(\mathrm{Cq})$ value for each clade-specific probe on each collection date were selected to run the qPCR assays in triplicate. The first detection of $P$. cubensis sporangia for each clade was determined based on $\mathrm{Cq}$ values and disease development was monitored in sentinel plots based on visual inspection every other day until symptoms and signs were observed. After the initial detection of CDM, disease progress in each plot was monitored twice per week for 1 to 3 weeks and disease severity was recorded. Disease outbreaks in the surrounding counties and states monitored by the CDM ipmPIPE system

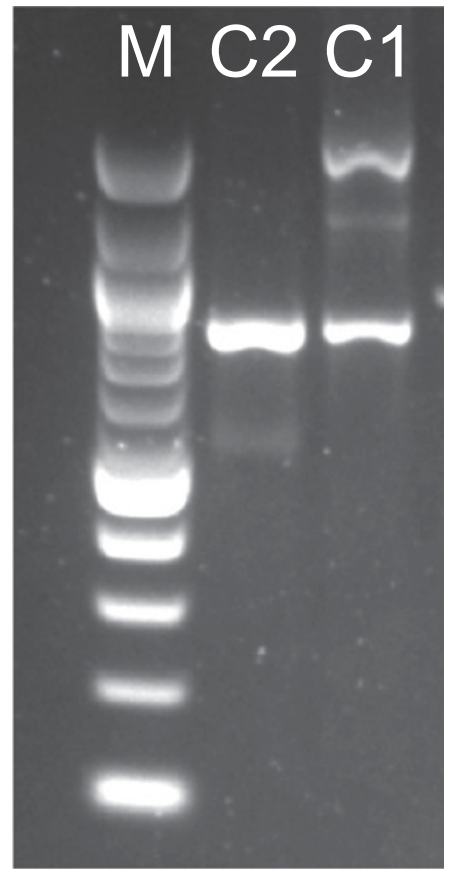

Fig. 1. Confirmation of c2555.3e7 described by Withers et al. (2016) as a marker of Pseudoperonospora cubensis clades described by Wallace et al. (2020). Gel with a 100-bp ladder (M) showing the c2555.3e7 PCR amplicons of clade 2 (C2) isolate MSU1 and clade 1 (C1) isolate SC1982 using primers sw552 and sw553 designed by Withers et al. (2016). 
(Ojiambo et al. 2015) were also compared with the timing of $P$. cubensis sporangia detection and with visual disease diagnosis in the sentinel plots.

Analysis of qPCR inhibition and IC. Silicone grease and other particles were routinely captured by the sampling rods. Thus, the efficiency of the multiplex qPCR assay was determined by amplifying genomic DNA of SC1982 and MSU-1 sporangia in the presence of $2 \mathrm{ml}$ of eluate from CDM disease-free field sampler rods and analyzing as previously described (Kunjeti et al. 2016). Additionally, an IC, as described previously (Haudenshield and Hartman 2011; Kunjeti et al. 2016), was designed to identify any alterations in amplification efficiency in the presence of field spore trap sample eluate. Primers and probes for the amplification and

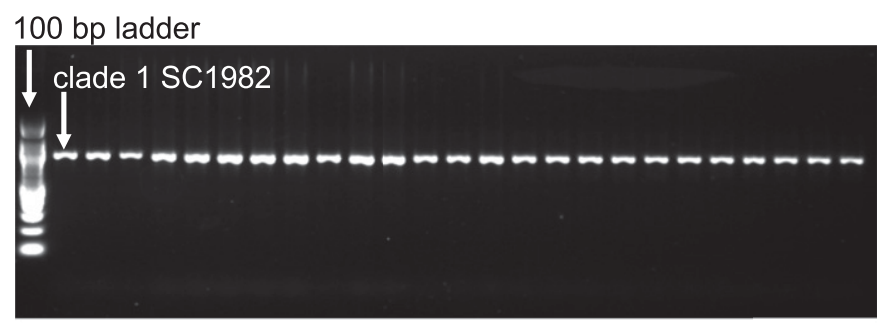

$100 \mathrm{bp}$ ladder

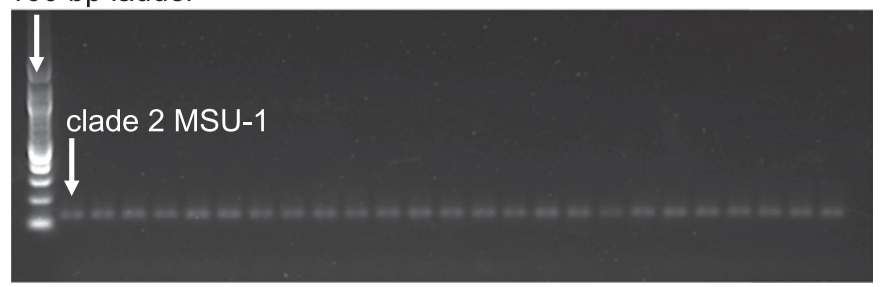

Fig. 2. Gel images of c2555.3e7 PCR amplicons of clade 1 ( 829 bp, top) and clade 2 (128 bp, bottom) Pseudoperonospora cubensis sporangia DNA using primers ar1517 and sw553. Clade 1 and clade 2 isolates used in the gel are (from left to right) as follows. Clade 1: KIN2-6-4, 14KIN2-6-6A, 14WAY2-62A, WAY2-4-15, WAY2-4-14, 14KIN2-4-3B, WAY2-5-14, 14CLE2-5-4C, CLE-7-11, and CLE-7-7. Clade 2: KIN-1-7, KIN-1-10, CLE-1-2, 14CLE2-12B, 14CLE2-1-11A, 14KIN-3-5D, 14KIN-3-1C, 14KIN2-3-2A, 14CLE-3-8, 14WAY2-3-1B quantification of the IC were designed with a similar Ta as that of clade 1 and clade 2 . A standard curve of IC was prepared using 10fold serial dilutions ranging from $100 \mathrm{fM}$ to $1 \mathrm{aM}$ using IC-specific primers and probes in a singleplex qPCR (Table 2; Supplementary Fig. S2). Afterward, $10 \mathrm{aM}$ of IC oligonucleotide was used as a target in singleplex qPCR assays with each of the 2-ml spore trap samples to identify any significant shift in IC quantification cycle (Cq) (Supplementary Fig. S3).
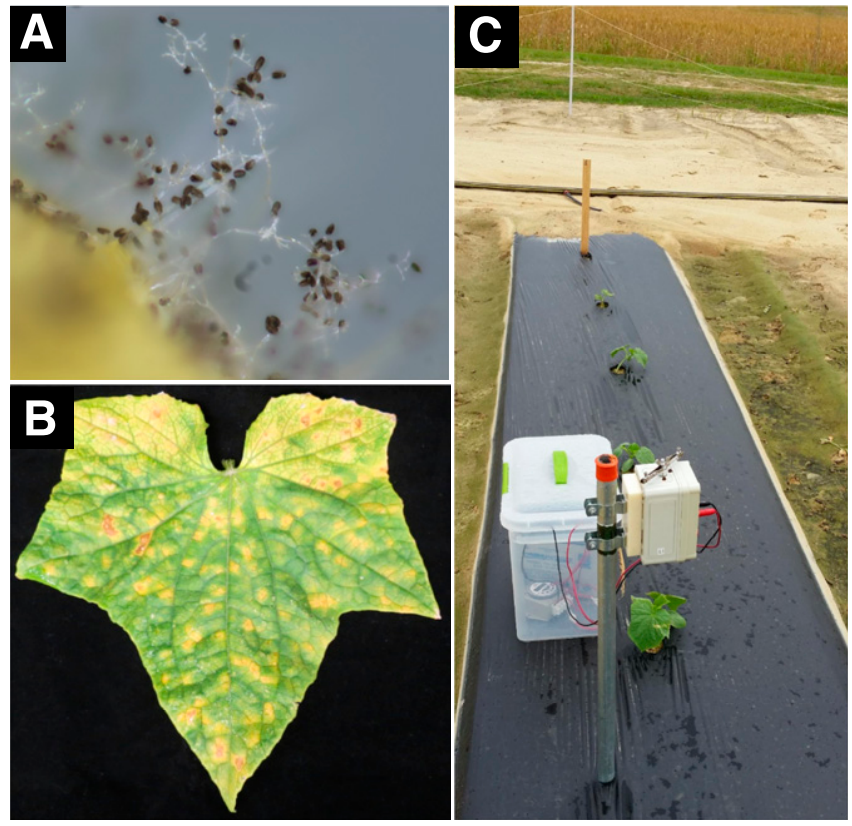

Fig. 3. A, Pseudoperonospora cubensis sporangia and sporangiophores on cucumber leaf surface; $\mathbf{B}$, cucumber leaf infected with cucurbit downy mildew and showing characteristic chlorotic, angular lesions delimited by leaf veins; and $\mathbf{C}$, a rotorod spore trap setup in a cucumber sentinel plot at the Central Crops Research Station in Clayton, NC (early to mid-May 2016).

TABLE 2. Primers and probes used in this study ${ }^{\mathrm{a}}$

\begin{tabular}{|c|c|c|c|c|}
\hline Assay, ID & Description & Sequence $\left(5^{\prime}\right.$ to $\left.3^{\prime}\right)$ & $\begin{array}{c}\mathrm{Ta} \\
\left({ }^{\circ} \mathrm{C}\right)\end{array}$ & $\begin{array}{l}\text { Product size } \\
\text { (bp) }\end{array}$ \\
\hline \multicolumn{4}{|l|}{ Multiplex } & N/A \\
\hline \multicolumn{5}{|c|}{ Clade 1 (SC1982) } \\
\hline $\operatorname{ar} 1488$ & Clade 1 uniplex forward primer & GGAGACTTTGTGCTCTGGTCGTT & 61.2 & 68 \\
\hline $\operatorname{ar} 1495$ & Universal clade 1 reverse primer & CGCAGTGGTTGGGTGTGT & 60.5 & 111 \\
\hline $\operatorname{ar} 1497$ & Clade 1 universal probe & HEX-CAG+TAGCA+TAACCCAAG+ACTTCGT-IABkFQ & 69.4 & N/A \\
\hline \multicolumn{5}{|c|}{ Clade 2 (MSU-1) } \\
\hline $\operatorname{ar} 1498$ & Clade 2 uniplex probe & FAM- TG+CTGGAGA+CT+TTGTGCTCT-IABkFQ & 59.2 & N/A \\
\hline $\operatorname{ar} 1529$ & Clade 2 multiplex probe & FAM-TGGTCGAGC+ATTGACAAGAGCCTATCC-IABkFQ & 69.9 & N/A \\
\hline $\operatorname{ar} 1531$ & Clade 2 multiplex reverse primer & CCATCAAGCCAGCAACTTGTT & 59.7 & 93 \\
\hline ar357 & Sequencing primer of L- and S-SC1982 & CGTTGTCCAGGCAAATATAAAT & $\ldots$ & N/A \\
\hline $\operatorname{ar} 538$ & Sequencing primer of L- and S-SC1982 & GTATCTTCTCGACCATCTCTTC & $\ldots$ & N/A \\
\hline $\operatorname{ar} 907$ & Sequencing primer of L-SC1982 & AGTGGACGTACGAACTTCATA & $\ldots$ & N/A \\
\hline $\operatorname{ar957}$ & IC forward primer & ATCCGCTTCCTGTACGAGTCAA & 60.6 & 121 \\
\hline sw553 & c2555.3e7 reverse primer & TGCGCTCGAGTATCTTCTACC & 59.4 & \\
\hline $\operatorname{ar} 1492$ & Forward primer psc-contig 1588 & CCAGACCATGCATTAGCGGAT & 60.5 & 899 \\
\hline $\operatorname{ar} 1479$ & Reverse primer psc-contig 1588 & CCAGTCGAGAACAAGTTTGATACGA & 61.1 & $\ldots$ \\
\hline
\end{tabular}

a Product sizes and annealing temperatures (Ta) are indicated for primers used for amplification. All primers and probes were designed herein, with the exception that primers sw552 and sw553 were designed by Withers et al. (2016). For probes, $+\mathrm{A}$ or $+\mathrm{T}$ indicate locked nucleotides in the probes. IC $=$ internal control, IABkFQ = Iowa BlackÒ, and N/A = not available. 
Data analyses. Samples were run in triplicate with at least three biological replicates whenever possible. Data analysis was performed as described previously (Klosterman et al. 2014; Kunjeti et al. 2016). The relationship between $\mathrm{Cq}$ values and number of sporangia or genomic DNA was determined using linear regression. Numbers of sporangia per sample were estimated based on standard curves derived from the regression analysis. Efficiency of the qPCR was analyzed using the formula $\left[-1+10^{(-1 / \text { slope })}\right] \times 100$.

\section{RESULTS}

Sequence analyses of the marker gene $2555.3 \mathrm{e} 7$ polymorphic DNA region. The primers sw552 and sw553 amplified single PCR fragments for isolates collected from cucumber, cantaloupe, and buffalo gourd, whereas isolates from watermelon, pumpkin, and butternut squash generated two amplicons; one of a similar size and an additional, larger amplicon. Similar results were observed when these primers were used to amplify genomic DNA of isolates SC1982 (clade 1) and MSU-1 (clade 2). Upon sequence analysis, MSU-1 produced a single fragment of $787 \mathrm{bp}$ in length and SC1982 produced two fragments, one of 785 bp (called small or S-SC1982) and a second of 1,488 bp (called large or L-SC1982) (Fig. 1). The polymorphic nucleotide region in c2555.3e 7 among these three sequenced fragments was identified and aligned to the MSU-1 genome (Supplementary Fig. S1). The conserved nature of the first $710 \mathrm{bp}$ of c2555.3e7 between L-SC1982 and MSU-1 allowed for universal forward primer ar1517 to be designed for further validation of the polymorphism identified (Table 2). However, the c2555.3e7 nucleotide sequence from 711 to $790 \mathrm{bp}$ of MSU-1 and SC1982 exhibited considerable polymorphism, with a total of $92.3 \%$ sequence identity. Substantially lower sequence identity was observed between L-SC1982 and S-SC1982 (77\%) and S-SC1982 and MSU-1 (80.5\%). Additionally, the nucleotide sequences between 790 and 1,440 bp of L-SC1982 were almost identical with part of psc-contig-1588 of MSU-1.

Clade-specific assay specificity. Sequence variability between SC192 and MSU-1, near the 3' end of c2555.3e7, allowed for primers ar1517 and sw553 to amplify the marker and determine the host-related clade of the additional 97 P. cubensis isolates. When DNA from isolates collected from watermelon, pumpkin, butternut squash, and acorn squash were PCR amplified, an 829-bp fragment was observed, whereas a fragment of $128 \mathrm{bp}$ was noted in all isolates from cucumber and cantaloupe (Fig. 2; Table 1; Supplementary Table S1). None of the other oomycete or host plant sample PCR amplifications generated any matching PCR products. These 97 $P$. cubensis isolates were also tested for clade identity using the multiplex qPCR assay. The two tests were in agreement for all isolates collected from cucumber and watermelon; however, 18 isolates collected from pumpkin, butternut squash, cantaloupe, and acorn squash exhibited $\mathrm{Cq}$ values for primers specific to both clades.

Specificity, sensitivity, and efficiency of the qPCR assay. The amplification of the multiplex qPCR assays for sporangial DNA of isolates SC1982 and MSU-1 exhibited a significant linear response, with an efficiency of $105.04 \%\left(R^{2}=0.996\right)$ and $100.5 \%$ $\left(R^{2}=0.998\right)$, respectively (Fig. 4). Linearity and efficiency of the singleplex qPCR for both isolates were also similar (data not shown). Simultaneous detection using equal and unequal concentrations of DNA from both clades consistently demonstrated unhindered linearity at all tested DNA concentrations. No significant differences in $\mathrm{Cq}$ values were observed for SC1982 and MSU-1 when DNA was combined compared with that of singleclade DNA in a multiplex reaction (data not shown). However, detection of genomic DNA concentrations $<100 \mathrm{fg}$ was unreliable; therefore, the lower limit of detection of all qPCR assays was considered to be $100 \mathrm{fg}$ of $P$. cubensis genomic DNA regardless of clade. Although the HEX-labeled LNA probe for clade 1 on rare occasions exhibited nonspecific $\mathrm{Cq}$ values for clade 2 total genomic DNA at a concentration $\geq 1 \mathrm{ng}(\mathrm{Cq}>45)$, reducing the cycle number to 38 for the multiplex qPCR eliminated any nonspecific detection without losing sensitivity.

Significant linear relationships were observed between sporangial count DNA and $\mathrm{Cq}$ values for both clades of $P$. cubensis in the multiplex qPCR assay. The amplification of the multiplex qPCR assays for clade 1 isolate SC1982 and clade 2 isolate MSU-1 sporangial counts exhibited a linear response with an efficiency of $109.81 \%\left(R^{2}=0.911\right)$ and $95.5 \%\left(R^{2}=0.933\right)$, respectively (Fig. 5). However, none of the qPCR assays were able to detect $<10$ sporangia and, therefore, the detection threshold was considered to be the DNA concentration associated with $\geq 10$ sporangia. Similar linear relationships were also observed in the singleplex qPCR assays (data not shown). Simultaneous detection of equal and unequal sporangia counts for DNA from both clades did not show any effect on the $\mathrm{Cq}$ values for each clade (data not shown).

Detection and quantification of $P$. cubensis sporangia from spore traps. In total, 84 and 79 total spore samples were collected in 2016 and 2017, respectively, from the sentinel plots located at the CCRS and CURS. The clade-specific multiplex qPCR
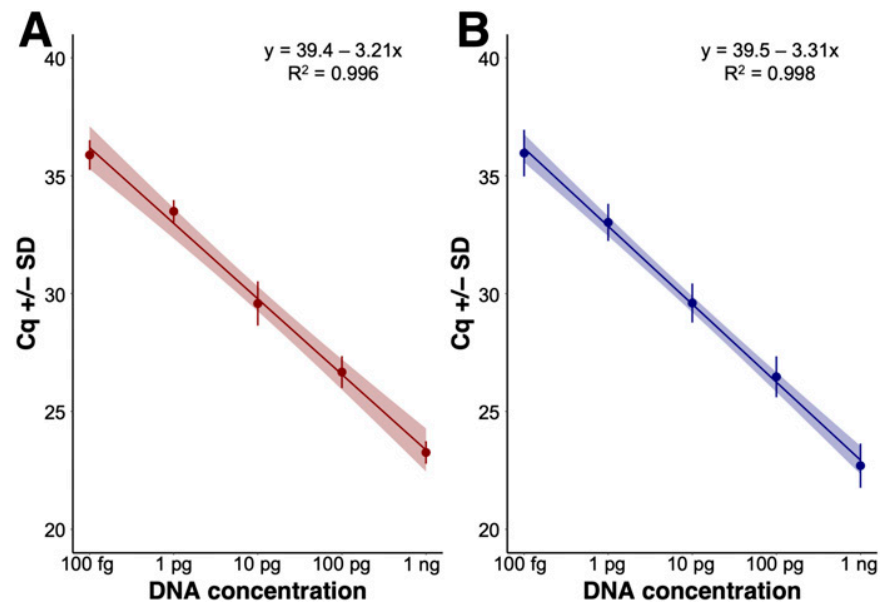

Fig. 4. Standard curves of the multiplex quantitative PCR based on $\log _{10^{-}}$ transformed DNA concentrations for A, SC1982 (clade 1) and B, MSU-1 (clade 2). A linear trend is observed in both cases, the shaded areas above the line represent $95 \%$ confidence intervals, $\mathrm{Cq}=$ cycle threshold, and the error bars represent the standard deviations (SD).
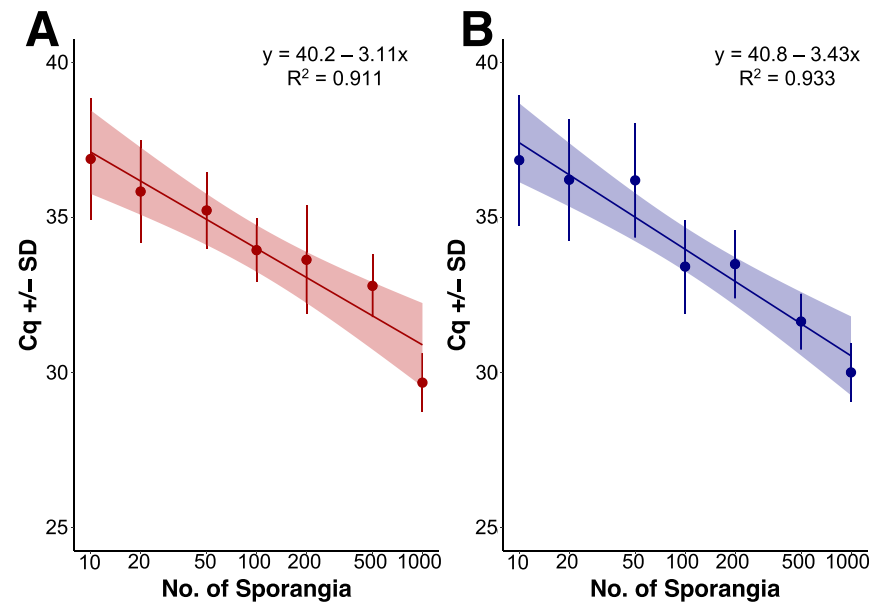

Fig. 5. Standard curves of the multiplex quantitative PCR based on $\log _{10^{-}}$ transformed sporangia counts for A, SC1982 (clade 1) and B, MSU-1 (clade 2). A linear trend is observed in both cases, the shaded areas above the line represent $95 \%$ confidence intervals, $\mathrm{Cq}=$ cycle threshold, and the error bars represent the standard deviations (SD). 
assay detected the presence of airborne $P$. cubensis sporangia from these samples (Fig. 6; Supplementary File S1) and the resulting Cq values were then compared with the previously described standard curves to estimate an approximate sporangia count (Fig. 5). In 2016, clade 2 sporangia were first observed on 7 and 5 July in spore samples collected from the early-season sentinel plots located at the
CCRS and CURS, respectively, and the resulting mean Cq values were equal to approximately 67 and 50 sporangia/sample at CCRS and CURS, respectively. Likewise, in the late-season sentinel plots, clade 2 sporangia were first observed in spore samples collected on 7 September at the CCRS and on 23 August at the CURS, with mean $\mathrm{Cq}$ values equivalent to approximately 43 and 50 sporangia/sample,

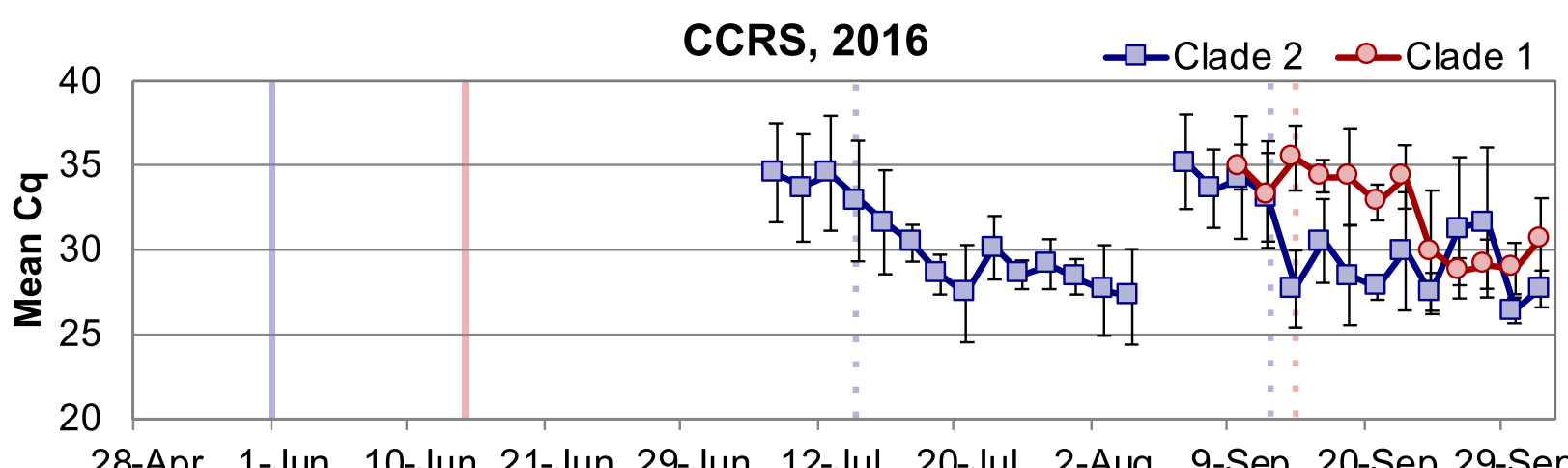

28-Apr 1-Jun 10-Jun 21-Jun 29-Jun 12-Jul 20-Jul 2-Aug 9-Sep 20-Sep 29-Sep

CURS, 2016

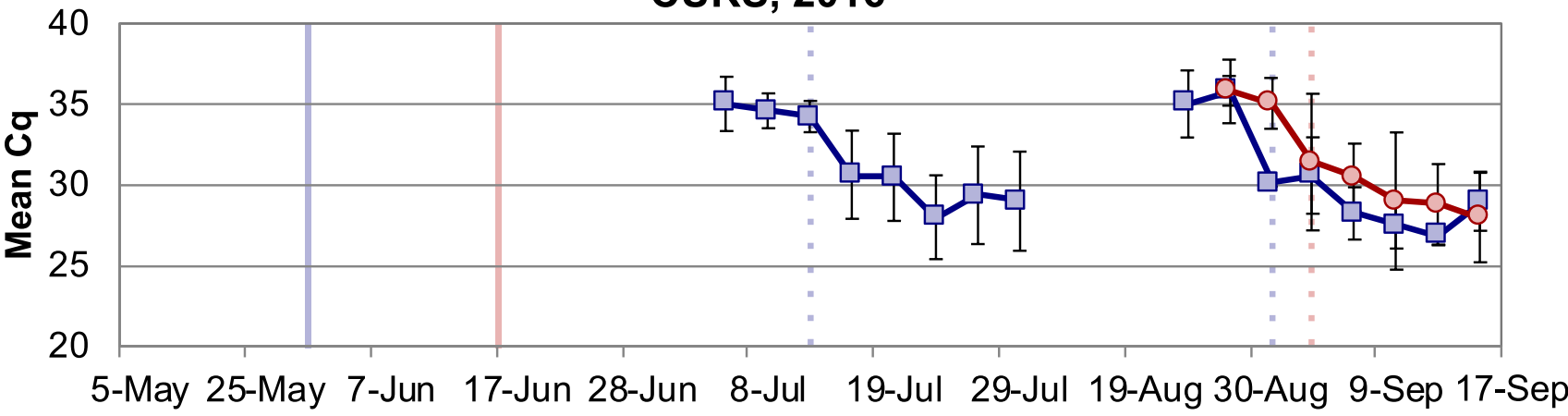

CCRS, 2017

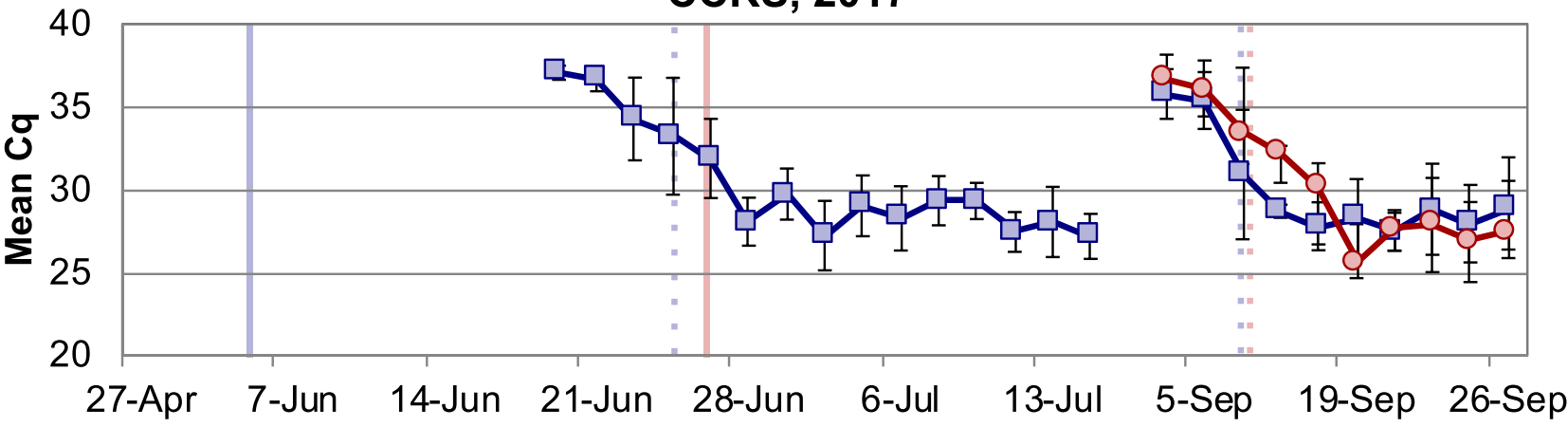

CURS, 2017

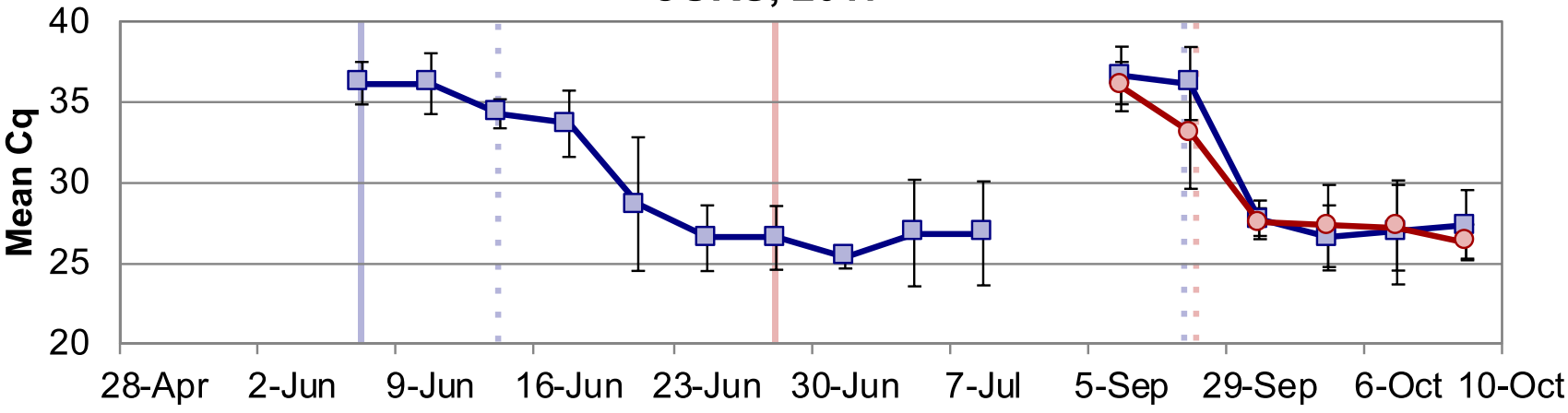

Fig. 6. Pseudoperonospora cubensis clade 1 and clade 2 sporangia detected with quantitative PCR in spore trap samples collected at the Central Crops Research Station (CCRS) and the Cunningham Research Station (CURS) in 2016 and 2017. Cq = cycle threshold. The gap between plots represents two plantings of the sentinel plots. Solid vertical lines indicate the first report to the cucurbit downy mildew ipmPIPE of a host susceptible to a clade in North Carolina. Dotted vertical lines indicate visual confirmation ( $<5 \%$ disease) of infection of a host susceptible to a clade in the sentinel plots. 
respectively. Clade 1 sporangia were not observed in the earlyseason sentinel plots but were detected in the late-season planting on 9 September at the CCRS and on 26 August at the CURS, with mean $\mathrm{Cq}$ values equivalent to approximately 51 and 54 sporangia/ sample, respectively. In 2017, the early-season sentinel plots saw clade 2 sporangia arrive at the CCRS on 20 June and at the CURS on 6 June, with mean $\mathrm{Cq}$ values equivalent to approximately 31 and 23 sporangia/sample, respectively. Clade 2 sporangia were first detected in the late-season sentinel plots on 1 September at the CCRS and on 5 September at the CURS, with mean Cq values equivalent to 30 and 17 sporangia/sample, respectively. Similar to 2016, clade 1 sporangia were not detected in the early-season sentinel plots at either location but were observed in the late-season sentinel plots at the CCRS on 1 September and at the CURS on 5 September, with mean $\mathrm{Cq}$ values equivalent to 23 and 26 sporangia/ sample, respectively (Fig. 6).

When comparing detection of clade 1 or clade 2 sporangia using the spore samplers and the clade-specific assay with visual confirmation of downy mildew in the sentinel plots and outbreak reports made to the CDM ipmPIPE, we found that disease or sporangia were not detected in the sentinel plots in spite of CDM being reported in the state (Fig. 5). Based on the public records of the CDM ipmPIPE, the first detection of disease in North Carolina was on 1 June 2016 and 5 June 2017 in cucumber in Duplin County, with cucumber being a clade 2 host. The first detection of CDM on a clade 1 host (watermelon for both reports) was on 17 June 2016 in Nash County and 27 June 2017 in Carteret County. In contrast, disease was first confirmed in the cucumber (clade 2) sentinel plot on 13 July and 13 September 2016 for the first planting and 23 June and 6 September 2017 for the second planting at the CCRS, and on 12 July and 30 August 2016 for the first planting and 13 June and 8 September 2017 for the second planting at the CURS (Fig. 5). CDM was confirmed in the squash (clade 1) sentinel plot on 14 September 2016 and 6 September 2017 for the second planting at the CCRS, and on 2 September 2016 and 8 September 2017 for the second planting at the CURS (Fig. 5).

Symptom development (disease severity $<5 \%$ ) in the sentinel plots was observed between 2 and 4 days after sporangia for the respective clades were detected using the spore samplers and multiplex qPCR (Fig. 6). Based on the spore sampler detection trends, CDM symptoms were typically observed within 1 to 2 days after $\mathrm{Cq}$ values became lower than approximately 36.7 for both clades and locations, which corresponds to approximately 10 to 20 sporangia (Fig. 5). For both clades, the number of detected sporangia increased as CDM progressed throughout the sentinel plots, as indicated by the gradual decrease of $\mathrm{Cq}$ values in the assay.

Analysis of multiplex qPCR inhibition. Genomic DNA extracted from spore samples collected in early May from the CCRS and CURS was used as P. cubensis sporangia DNA-free eluate to evaluate any inhibition of the multiplex qPCR assay. During that period of time, sentinel plots had just been planted and no CDM disease was recorded in the state (Fig. 6). When the eluates were added to the sporangial DNA of either SC1982 or MSU-1, the 10fold serial dilution series showed no significant change in Cq values (data not shown). To test whether the $P$. cubensis sporangia DNApositive spore samples had any qPCR inhibitors present, an IC control singleplex qPCR method was employed. The standard curve of IC that was generated using 10-fold serial dilutions ranging from $100 \mathrm{fM}$ to $1 \mathrm{aM}$ exhibited complete linearity, with a slope of -3.26 (Supplementary Fig. S2). When $10 \mathrm{aM}$ of IC was used as the template DNA in the IC qPCR assays with each of the spore-trappositive samples, no significant change in $\mathrm{Cq}$ values was observed (Supplementary Fig. S3).

\section{DISCUSSION}

In this study, a polymorphic diagnostic marker, c2555.3e7 (Withers et al. 2016), was used to develop an end-point PCR and probe-based multiplex qPCR assay to detect and quantify sporangia of $P$. cubensis belonging to host-specialized clades (Wallace et al. 2020). Our assay had a detection limit of $100 \mathrm{fg}$ greater than described previously for $P$. cubensis (Summers et al. 2015a); however, it exhibited enhanced specificity and sensitivity when using different sporangial count DNA. The Summers et al. (2015a) multiplex qPCR assay based on a single nucleotide polymorphism (SNP) in the mitochondrial cox2 region allowed for the differentiation of $P$. cubensis and $P$. humuli isolates (Summers et al. 2015a). The Summers et al. (2015a) assay was also used to detect airborne sporangia captured in rotorod spore trap samples with a detection limit as low as $1 \mathrm{fg}$ of $P$. cubensis DNA and 10 sporangia, similar to our assay. However, the Summers et al. (2015a) assay did not differentiate between the $P$. cubensis clades in airborne sporangia because they were only recently reported (Wallace et al. 2020). The assays developed here are a crucial first step toward a biosurveillance system that will help to better inform fungicide application timing on specific cucurbit crops based on the host-adapted clade of P. cubensis.

Real-time or qPCR assays have been developed to detect airborne downy mildew propagules and are typically based on SNPs in a particular nuclear or mitochondrial gene. The c2555.3e7 marker used here is a species-specific, single-copy nuclear gene identified through comparative genomics, validated against multiple distant and closely related oomycete species, and with no cross-detection to closely related species (Withers et al. 2016). In contrast, a real-time PCR assay utilizing an SNP in the $18 \mathrm{~S}$ ribosomal DNA to detect propagules of the spinach downy mildew pathogen Peronospora effusa showed cross detection to the sugar beet downy mildew pathogen $P$, schachtii at a limit of $100 \mathrm{fg}$ in air currents using spore samplers (Klosterman et al. 2014). Single-copy markers based on nuclear DNA, like c2555.3e7, or low-copy number markers based on nuclear ribosomal DNA (nrDNA) such as the internal transcribed spacer, may also offer more accuracy for sporangia quantification compared with high-copy target markers based on mitochondrial DNA (mtDNA). Recently, an nrDNA-based marker provided more accurate quantification of multiple arbuscular mycorrhizal fungi than an mtDNA marker due to the correlation between nrDNA copy number and fungal biomass (Voř́ršková et al. 2017). The number of mitochondria in an individual oomycete sporangium is not well documented but may vary from 50 to 200 in individual yeast cells (Freel et al. 2015). Although this variability may allow for mtDNA markers to detect sporangia at lower DNA concentrations, the accuracy in detecting specific amounts of sporangia may be greatly reduced. Thus, using single-copy nuclear DNA markers in qPCR assays to quantify airborne sporangia may provide greater quantification capabilities than mtDNA markers, which is critical when developing a biosurveillance system that depends on accurate estimation of clade-specific Pseudoperonospora cubensis inoculum to determine the likelihood of CDM on specific cucurbit crops.

Genomic DNA extracted from P. cubensis sporangia and from CDM-symptomatic leaf lesions were analyzed using the end-point PCR and multiplex qPCR assays. When leaf lesions from cucumber and watermelon were evaluated, only DNA of clade 1 was observed in watermelon leaf lesions, and only DNA of clade 2 was observed in cucumber leaf lesions. These results support previous findings that isolates of $P$. cubensis display host adaptation (QuesadaOcampo et al. 2012; Summers et al. 2015b; Thomas et al. 2017) and provides further evidence that host preference in isolates of $P$. cubensis is linked with the two clades described by Wallace et al. (2020). Previous research revealed that clade 2 isolates of $P$. cubensis preferentially infect cucumber and cantaloupe, with clade 1 isolates occurring at lower levels $(<2 \%$ in cucumber and $<20 \%$ in cantaloupe) in these hosts (Wallace et al. 2020). In this study, when analyzing 58 DNA samples collected from pumpkin, butternut squash, acorn squash, and cantaloupe leaf lesions, 18 were found to be positive for both clade 1 and clade 2 corresponding to $56 \%$ of pumpkin, $26 \%$ of acorn squash, and $28 \%$ of cantaloupe samples. As reported by Wallace et al. (2020), our findings show 
that $P$. cubensis clades display host adaptation but not complete host specificity. At the present time, it is unclear whether pathogen, host, or environmental factors allow for a specific cucurbit host to harbor both clades. Throughout the course of this study, detached cucumber leaves were infected with $P$. cubensis isolates to maintain a constant source of sporangia. The older cucumber leaves seemed to support greater infection and sporulation of clade 1 isolates than did the younger leaves; clade 2 isolates were able to infect and sporulate on detached cucumber leaves regardless of their age and size (data not shown). Plant host resistance can vary with plant age or tissue maturity but evidence of a shift from resistance to susceptibility seems to be lacking (Develey-Rivière and Galiana 2007), and whether similar circumstances will lead to both clades of $P$. cubensis infecting pumpkin and squash should be explored further.

Spore trapping has been utilized to detect $P$. cubensis sporangia previously and provides an early warning system for fungicide application timing (Neufeld et al. 2013). However, combining spore traps with real-time qPCR has provided greater precision when identifying sporangia in air currents for other downy mildew pathogens (Klosterman et al. 2014; Kunjeti et al. 2016). Thus, in this study, sentinel plots were planted to cucumber and watermelon for two cropping periods within each growing season (spring to summer and summer to fall) and the clade-specific multiplex qPCR assay was validated by capturing airborne sporangia using rotorod impaction spore samplers. Interestingly, the results generated through assay validation provide further evidence of host preference as well as seasonal differences between the clades at both research stations.

Managing CDM requires the frequent application of effective fungicides but efficacy tests are often performed solely on cucumber, with the results applied to other cucurbit crops (Goldenhar and Hausbeck 2019; Holmes et al. 2015; Keinath et al. 2019). Improving our knowledge of fungicide efficacy on other cucurbit hosts such as those preferred by clade 1 isolates (e.g., watermelon) could lead to fungicide recommendations for the specific cucurbit hosts based on clade. At present, cucurbit growers are encouraged to initiate preventive fungicide applications for downy mildew when an outbreak in a neighboring state has been reported to the CDM ipmPIPE, regardless of specific cucurbit host plant (Ojiambo et al. 2011). The host preferences described here and previously (Wallace et al. 2020) indicate that CDM should be managed based on the specific host affected. Managing CDM in a host-specific manner could reduce unnecessary fungicide applications by recommending that applications be initiated only after a report occurs on a specific crop in an adjacent state, which could also slow the development of fungicide resistance by reducing selective pressure.

Seasonal variation, where clade 2 sporangia and CDM on a clade 2 host was observed earlier in the growing season compared with clade 1 sporangia or CDM on a clade 1 host, occurred in both years of this study. Indeed, clade 2 sporangia were observed prior to CDM symptoms in the early-season cucumber plots at both field sites in both years. Likewise, clade 2 sporangia were observed prior to CDM symptoms in the late-season cucumber plots at both field sites in both years. Symptoms were not observed in early-season watermelon plots at either field site over the 2 years but CDM did occur in late-season watermelon shortly after clade 1 sporangia were identified in the spore traps. These results corroborate those of a previous study, where clade 1 sporangia were more prevalent in the fall and clade 2 sporangia were more prevalent in the summer (Wallace et al. 2020). However, in that study, symptomatic leaf tissue was collected at only two time points (summer and fall) per year for 2 years. Thus, using the spore samplers to collect sporangia every 2 to 4 days from May to September provided greater precision and confirmed the previously observed seasonality of the two clades (Wallace et al. 2020). As mentioned previously, CDM management is heavily reliant on chemical control but fungicide efficacy appears to vary by state and year (Keinath et al. 2019). The geographic variation in efficacy could be related to clade, though that has not been formally investigated. Additionally, these fungicide applications could be preferentially controlling clade 1 isolates early in the growing season, resulting in epidemics caused by clade 2 isolates. However, whether that seasonal variation is the result of isolates of the respective clades differing in their response to fungicides is unknown and warrants further investigation. The seasonal differences observed here could also be a side effect of the total area planted to hosts susceptible to these two clades in North Carolina over the 2 years. Cucurbit producers in North Carolina typically plant greater hectarage to cucumber compared with watermelon and, in 2016, approximately 4,452 ha were planted to cucumber compared with only 2,671 ha of watermelon (NASS 2018). Similarly, in 2017 , approximately 4,249 ha were planted to cucumber compared with 2,711 ha planted to watermelon (NASS 2018). That nearly twice as many hectares were planted to cucumber may have allowed for clade 2 sporangia to proliferate and spread across the state much faster than clade 1 sporangia. Neither clade 1 sporangia nor CDM symptoms on watermelon were observed in the sentinel plots before August of either year, despite being observed in North Carolina by late June of both years. Whether this phenomenon occurs in other states where cucurbit production occurs remains to be seen but future nationwide monitoring using the clade-specific marker described in this study would be useful to fully understand seasonal dynamics in the respective $P$. cubensis clades.

Utilizing the observed polymorphism in marker c2555.3e7 described by Withers et al. (2016), an end-point PCR and probebased multiplex qPCR assay were developed to detect and quantify $P$. cubensis sporangia belonging to the host-adapted clades (Wallace et al. 2020). The multiplex assay was used in conjunction with rotorod impaction spore samplers and detected sporangia of both clade 1 and clade 2 between 2 and 4 days prior to disease onset on watermelon and cucumber sentinel plots, respectively. Current CDM management recommendations call for protective fungicide applications to protect all cucurbits, regardless of host, once a report has been submitted to the CDM ipmPIPE from a neighboring state. In 2016, CDM was first reported in North Carolina on 1 June and was observed on cucumber test plots at the CCRS and CURS a little over a month later but wasn't observed on watermelon plots at either station until 26 August. Similarly, CDM was reported in North Carolina on 5 June 2017 and was observed the next day at the CURS and within 2 weeks at the CCRS; however, once again, CDM was not observed on watermelon until 1 September, likely due to seasonal variation of the respective clades. With the exception of the cucumber plots at the CURS in 2017, all observations of CDM in cucumber or watermelon sentinel plots occurred beyond the recommended interval between fungicide applications, which would have been unnecessary due to the lack of inoculum in the local air currents. Thus, deploying spore sampling systems, either stationary or attached to unmanned aerial vehicles, and analyzing the samples with the multiplex qPCR assay developed here will act as a complement to the CDM ipmPIPE and allow for significant improvements in the detection of $P$. cubensis sporangia and prediction of CDM epidemics. Such improvements will enable CDM disease management practices such as fungicide applications to be employed only on crops at risk of infection at any given time throughout the growing season, based on detection of the specific P. cubensis clade.

\section{ACKNOWLEDGMENTS}

We thank all the members of the Quesada lab for their valuable help and $\mathrm{S}$. Isard for providing the rotorod spore traps used in this study.

\section{LITERATURE CITED}

Beans, C. 2018. Scientists Are Fighting For The Stricken Pickle Against This Tricky Disease. National Public Radio. https://www.npr.org/sections/thesalt/2018/12/14/672229450/scientists-are-fighting-for-the-stricken-pickleagainst-this-tricky-disease 
Bustin, S. A., Benes, V., Garson, J. A., Hellemans, J., Huggett, J., Kubista, M., Mueller, R., Nolan, T., Pfaffl, M. W., Shipley, G. L., Vandesopele, J., and Wittwer, C. T. 2009. The MIQE guidelines: Minimum information for publication of quantitative real-time PCR experiments. Clin. Chem. 55:611-622.

Call, A. D., Criswell, A. D., Wehner, T. C., Ando, K., and Grumet, R. 2012. Resistance of cucumber cultivars to a new strain of cucurbit downy mildew. HortScience 47:171-178.

Crandall, S. G., Rahman, A., Quesada-Ocampo, L. M., Martin, F. N., Bilodeau, G. J., and Miles, T. D. 2018. Advances in diagnostics of downy mildews: Lessons learned from other oomycetes and future challenges. Plant Dis. 102:265-275.

Develey-Rivière, M.-P., and Galiana, E. 2007. Resistance to pathogens and host developmental stage: A multifaceted relationship within the plant kingdom. New Phytol. 175:405-416.

Freel, K. C., Friedrich, A., and Schacherer, J. 2015. Mitochondrial genome evolution in yeasts: An all-encompassing view. FEMS Yeast Res. 15: fov023.

Goh, T. K. 1999. Single-spore isolation using a hand-made glass needle. Fungal Divers. 2:47-63.

Goldenhar, K. E., and Hausbeck, M. K. 2019. Fungicides for control of downy mildew on pickling cucumber in Michigan. Plant Health Prog. 20:165-169.

Granke, L. L., and Hausbeck, M. K. 2011. Dynamics of Pseudoperonospora cubensis sporangia in commercial cucurbit fields in Michigan. Plant Dis. 95:1392-1400.

Granke, L. L., Morrice, J. J., and Hausbeck, M. K. 2014. Relationships between airborne Pseudoperonospora cubensis sporangia, environmental conditions, and cucumber downy mildew severity. Plant Dis. 98:674-681.

Haudenshield, J. S., and Hartman, G. L. 2011. Exogenous controls increase negative call veracity in multiplexed, quantitative PCR assays for Phakopsora pachyrhizi. Plant Dis. 95:343-352.

Holmes, G. J., Ojiambo, P. S., Hausbeck, M. K., Quesada-Ocampo, L. M., and Keinath, A. P. 2015. Resurgence of cucurbit downy mildew in the United States: A watershed event for research and extension. Plant Dis. 99: 428-441.

Keinath, A. P., Miller, S. A., and Smart, C. D. 2019. Response of Pseudoperonospora cubensis to preventative fungicide applications varies by state and year. Plant Health Prog. 20:142-146.

Klosterman, S. J., Anchieta, A., McRoberts, N., Koike, S. T., Subbarao, K. V., Voglmayr, H., Choi, Y.-J., Thines, M., and Martin, F. N. 2014. Coupling spore traps and quantitative PCR assays for detection of the downy mildew pathogens of spinach (Peronospora effusa) and beet (P. schachtii). Phytopathology 104:1349-1359.

Kunjeti, S. G., Anchieta, A., Martin, F. N., Choi, Y.-J., Thines, M., Michelmore, R. W., Koike, S. T., Tsuchida, C., Mahaffee, W., Subbarao, K. V., and Klosterman, S. J. 2016. Detection and quantification of Bremia lactucae by spore trapping and quantitative PCR. Phytopathology 106: 1426-1437.

Naegele, R. P., Quesada-Ocampo, L. M., Kurjan, J. D., Saude, C., and Hausbeck, M. K. 2016. Regional and temporal population structure of Pseudoperonospora cubensis in Michigan and Ontario. Phytopathology 106:372-379.

NASS. 2018. North Carolina Agricultural Statistics Bulletin. United States Department of Agriculture National Agricultural Statistics Service. https:// www.nass.usda.gov/Statistics_by_State/North_Carolina/Publications/Annual_ Statistical_Bulletin/AgStat2018.pdf

Neufeld, K. N., Isard, S. A., and Ojiambo, P. S. 2013. Relationship between disease severity and escape of Pseudoperonospora cubensis sporangia from a cucumber canopy during downy mildew epidemics. Plant Pathol. 62: 1366-1377.

Ojiambo, P. S., Gent, D. H., Quesada-Ocampo, L. M., Hausbeck, M. K., and Holmes, G. J. 2015. Epidemiology and population biology of Pseudoperonospora cubensis: A model system for management of downy mildews. Annu. Rev. Phytopathol. 53:223-246.

Ojiambo, P. S., and Holmes, G. J. 2011. Spatiotemporal spread of cucurbit downy mildew in the eastern United States. Phytopathology 101:451-461.

Ojiambo, P. S., Holmes, G. J., Britton, W., Babadoost, M., Bost, S. C., Boyles, R., Brooks, M., Damicone, J., Draper, M. A., Egel, D. S., Everts, K. L., Ferrin, D. M., Gevens, A. J., Gugino, B. K., Hausbeck, M. K., Ingram, D. M., Isakeit, T., Keinath, A. P., Koike, S. T., Langston, D., McGrath, M. T., Miller, S. A., Mulrooney, R. P., Rideout, S., Roddy, E., Seebold, K. W., Sikora, E. J., Thornton, A., Wick, R. L., Wyenandt, C. A., and
Zhang, S. 2011. Cucurbit downy mildew ipmPIPE: A next generation Webbased interactive tool for disease management and extension outreach. Plant Health Prog. 12.

Purayannur, S., Miles, T. D., Gent, D. H., Pigg, S., and Quesada-Ocampo, L. M. 2020. Hop downy mildew caused by Pseudoperonospora humuli: A diagnostic guide. Plant Health Prog. 21:173-179.

Quesada-Ocampo, L. M., Granke, L. L., Olsen, J., Gutting, H. C., Runge, F., Thines, M., Lebeda, A., and Hausbeck, M. K. 2012. The genetic structure of Pseudoperonospora cubensis populations. Plant Dis. 96:1459-1470.

Rahman, A., Góngora-Castillo, E., Bowman, M. J., Childs, K. L., Gent, D. H., Martin, F. N., and Quesada-Ocampo, L. M. 2019. Genome sequencing and transcriptome analysis of the hop downy mildew pathogen Pseudoperonospora humuli reveal species-specific genes for molecular detection. Phytopathology 109:1354-1366.

Rahman, A., Miles, T. D., Martin, F. N., and Quesada-Ocampo, L. M. 2017. Molecular approaches for biosurveillance of the cucurbit downy mildew pathogen, Pseudoperonospora cubensis. Can. J. Plant Pathol. 39:282-296.

Rodriguez, A., Rodriguez, M., Cordoba, J. J., and Andrade, M. J. 2015. Design of primers and probes for quantitative real-time PCR methods. Pages 31-56 in: PCR Primer Design. C. Basu, ed. Methods in Molecular Biology, vol. 1275. Humana Press, New York, NY, U.S.A.

Runge, F., and Thines, M. 2009. A potential perennial host for Pseudoperonospora cubensis in temperate regions. Eur. J. Plant Pathol. 123:483-486.

Salcedo, A., Hausbeck, M., Pigg, S., and Quesada-Ocampo, L. M. 2020. Diagnostic guide for cucurbit downy mildew. Plant Health Prog. 21:166-172.

Savory, E. A., Adhikari, B. N., Hamilton, J. P., Vaillancourt, B., Buell, C. R., and Day, B. 2012a. mRNA-seq analysis of the Pseudoperonospora cubensis transcriptome during cucumber (Cucumis sativus L.) infection. PLoS One 7:e35796.

Savory, E. A., Granke, L. L., Quesada-Ocampo, L. M., Varbanova, M., Hausbeck, M. K., and Day, B. 2011. The cucurbit downy mildew pathogen Pseudoperonospora cubensis. Mol. Plant Pathol. 12:217-226.

Savory, E. A., Zou, C., Adhikari, B. N., Hamilton, J. P., Buell, C. R., Shiu, S.-H., and Day, B. 2012b. Alternative splicing of a multi-drug transporter from Pseudoperonospora cubensis generates an RXLR effector protein that elicits a rapid cell death. PLoS One 7:e34701.

Summers, C. F., Adair, N. L., Gent, D. H., McGrath, M. T., and Smart, C. D. 2015a. Pseudoperonospora cubensis and $P$. humuli detection using speciesspecific probes and high definition melt curve analysis. Can. J. Plant Pathol. 37:315-330.

Summers, C. F., Gulliford, C. M., Carlson, C. H., Lillis, J. A., Carlson, M. O., Cadle-Davidson, L., Gent, D. H., and Smart, C. D. 2015b. Identification of genetic variation between obligate plant pathogens Pseudoperonospora cubensis and $P$. humuli using RNA sequencing and genotyping-bysequencing. PLoS One 10:e0143665.

Thomas, A., Carbone, I., Choe, K., Quesada-Ocampo, L. M., and Ojiambo, P. S. 2017. Resurgence of cucurbit downy mildew in the United States: Insights from comparative genomic analysis of Pseudoperonospora cubensis. Ecol. Evol. 7:6231-6246.

Vořǐšková, A., Jansa, J., Püschel, D., Krüger, M., Cajthaml, T., Vosátka, M., and Janoušková, M. 2017. Real-time PCR quantification of arbuscular mycorrhizal fungi: Does the use of nuclear or mitochondrial markers make a difference? Mycorrhiza 27:577-585.

Wallace, E. C., Adams, M., Ivors, K., Ojiambo, P. S., and Quesada-Ocampo, L. M. 2014. First report of Pseudoperonospora cubensis causing downy mildew on Momordica balsamina and $M$. charantia in North Carolina. Plant Dis. 98:1279.

Wallace, E. C., D’Arcangelo, K. N., and Quesada-Ocampo, L. M. 2020. Population analyses reveal two host-adapted clades of Pseudoperonospora cubensis, the causal agent of cucurbit downy mildew, on commercial and wild cucurbits. Phytopathology 110:1578-1587.

Wallace, E. C., and Quesada-Ocampo, L. M. 2015. First report of downy mildew on buffalo gourd (Cucurbita foetidissima) caused by Pseudoperonospora cubensis in North Carolina. Plant Dis. 99:1861.

Wallace, E. C., and Quesada-Ocampo, L. M. 2017. Analysis of microsatellites from the transcriptome of downy mildew pathogens and their application for characterization of Pseudoperonospora populations. PeerJ 5:e3266.

Withers, S., Gongora-Castillo, E., Gent, D., Thomas, A., Ojiambo, P. S., and Quesada-Ocampo, L. M. 2016. Using next-generation sequencing to develop molecular diagnostics for Pseudoperonospora cubensis, the cucurbit downy mildew pathogen. Phytopathology 106:1105-1116. 